\title{
RAUL LINO E O PROGRAMA DECORATIVO DA ESCOLA PRIMÁRIA DE ALCÂNTARA - LISBOA (1917)
}

\author{
Raul Lino y el programa decorativo de la escuela primaria de \\ Alcântara - Lisboa (1917)
}

\section{Raul Lino and the decorative program of the Primary School of Alcântara - Lisboa (1917)}

\section{Carlos Manique da Silva ${ }^{\alpha}$}

Data de recepção 29/02/2020 • Data de aceitação 19/09/2020

«A school which cannot bring the arts to its pupil or its pupil to the arts has not completed its duty to the students, no matter what else it may have done for them». ${ }^{1}$

Resumo. Tendo como referência a Escola Primária de Alcântara (Lisboa) - desenhada pelo arquiteto Raul Lino, em 1915, e inaugurada um ano mais tarde -, a minha análise focar-se-á num conjunto de imagens (datado de 1917) pintadas nas paredes das salas de aula do mencionado edifício. A principal preocupação é perceber o impacto que as pinturas, na perspetiva do seu autor (Raul Lino), teriam na mente das crianças. Para o arquiteto - de formação anglo germânica, particularmente influenciado pelo movimento Arts \& Crafts - a imagem não era apenas decorativa; tratava-se de ajudar a criança a amar a Natureza e a arte, de educar o gosto e, mesmo, de desenvolver um sentimento patriótico (em causa, a formação do cidadão republicano). É nesse sentido que a educação estética emerge como programa social e político. Na mesma linha de pensamento, o currículo é concebido de modo abrangente, isto é, integrando conhecimentos ensinados e aprendidos em lições formais, assim

\footnotetext{
* Unidade de Investigação e Desenvolvimento em Educação e Formação (Instituto de Educação, Universidade de Lisboa), Alameda da Universidade, 1649-013 Lisboa. Portugal. manique@net.sapo. pt (D) https://orcid.org/0000-0003-4210-0723

${ }^{1}$ Charles Lang, 1938, citado em Sylvia Rhor, «Evolution of the Chicago Mural Movement. The Case of Lane Technical High School», em The Decorated School. Essays on the Visual Culture of Schooling, eds. Catherine Burke, Jeremy Howard e Peter Cunningham (Londres: Black Dog Publishing, 2013), 26.
} 
como valores e atitudes resultantes, por exemplo, do impacto da decoração escolar na memória individual e coletiva dos alunos. Metodologicamente interessa enfatizar que as fontes que valorizo não são apenas visuais. Com efeito, também mobilizo alguns textos escritos por Raul Lino, nomeadamente, correspondência ativa e artigos. Considero extremamente importante a triangulação das fontes. A análise das fontes visuais parte da descrição dos elementos presentes nas pinturas (na sua maioria, animais e elementos da $\mathrm{Na}$ tureza); ao mesmo tempo, procuro identificar as fontes que inspiraram o autor. Em relação a este último aspeto, importa sublinhar que Raul Lino foi ilustrador de livros para crianças, integrando essa experiência nos edifícios escolares que projetou.

Palavras-Chave: Raul Lino; Escola Primária de Alcântara - Lisboa; educação estética; fontes visuais; Portugal.

Resumen. Tomando como referencia la Escuela Primaria de Alcântara (Lisboa) - diseñada por el arquitecto Raúl Lino, en 1915, e inaugurada un año después -, mi análisis se centrará en un conjunto de imágenes (fechadas en 1917) pintadas en las paredes del aulas en ese edificio. La principal preocupación es comprender el impacto que las pinturas, en la perspectiva de su autor (Raúl Lino), tendrían en la mente de los niños. Para el arquitecto, de origen anglo-alemán, particularmente influenciado por el movimiento Arts \& Crafts, la imagen no era solo decorativa; se trataba de ayudar al niño a amar la naturaleza y el arte, educar el gusto e incluso desarrollar un sentimiento patriótico (en cuestión, la formación del ciudadano republicano). Es en este sentido que la educación estética surge como programa social y político. En la misma línea de pensamiento, el currículo se concibe de manera integral, es decir, abarcando los conocimientos enseñados y aprendidos en las lecciones formales, así como los valores y actitudes resultantes, por ejemplo, del impacto de la decoración escolar en la memoria individual y colectiva de los estudiantes. Metodológicamente, es interesante enfatizar que las fuentes que valoro no son solo visuales. De hecho, también movilizo algunos textos escritos por Raúl Lino, a saber, correspondencia activa y artículos. Considero extremadamente importante la triangulación de fuentes. El análisis de las fuentes visuales parte de la descripción de los elementos presentes en las pinturas (mayoritariamente animales y elementos de la naturaleza); al mismo tiempo, trato de identificar las fuentes que inspiraron al autor. Sobre este último aspecto, es importante destacar que Raúl Lino fue un ilustrador de libros para niños, integrando esta experiencia en los edificios escolares que diseñó.

Palabras clave: Raul Lino; Escuela Primaria Alcântara - Lisboa; educación estética; fuentes visuales; Portugal.

Abstract. Using as a reference the Primary School of Alcântara (Lisbon) - designed in 1815 by the architect Raul Lino and inaugurated one year later -, 
my analysis will focus on the decorative program (set of paintings, dated from 1917) on the walls of the classrooms of this building. My main goal is to examine the impact that the paintings, from the perspective of their author - Raul Lino, whose Anglo German education was strongly influenced by the Arts \& Crafts movement - would have on the children. For the architect, images was not just decorative. In fact, they were meant to help the children appreciate nature and art, to educate their sense of taste, and even to develop in them a patriotic sense (an agenda involving the formation of the republican citizen). In this sense, we see the emergence the of an aesthetic education as part of a more general social and political program. In line with the same idea, we can conceive of the curriculum in a wider sense, i. e., as including knowledge and skills obtained in formal lessons, but also values and attitudes received from the impact of school decoration on the students individual and collective memory. Methodologically, itis worth emphasizing that the sources I value are not just visual. In fact, some written texts by Raul Lino, namely, active correspondence and articles, are also used; the triangulation of several sources of evidence is very important. The analysis of the visual sources goes from the description of the elements present in the paintings (mostly, Nature and animals) to close observation of the sources that inspired the author. In relation to this last aspect, I should underline that Raul Lino was an illustrator of children's books, an experience that he integrated into the school buildings that he planned.

Keywords: Raul Lino; Escola Primária de Alcântara - Lisboa; aesthetic education; visual sources; Portugal.

\section{INTRODUÇÃO}

Conforme referiu Ian Grosvenor, ${ }^{2}$ a utilização das paredes da escola ou da sala de aula para expor imagens ou objetos tem uma história que remonta, pelo menos, ao século XviII. ${ }^{3}$ Certo é que, na centúria seguinte, à medida que a escola de massas se torna uma realidade, o recurso a esse

\footnotetext{
2 Ian Grosvenor, «"To Act on the Minds of Children”. Paintings into Schools and English Education», em The Black Boss of Schooling. A Cultural History of the Classroom, eds. Sjaak Braster, Ian Grosvenor e María del Mar del Pozo (Bruxelas: P.I.E. Peter Lang, 2011), 39-56.

${ }^{3}$ Podemos, certamente, recuar ao século xvII, uma vez que essa tecnologia didática foi preconizada e sistematizada, em muitos aspetos, por Comenius. No caso português, é exemplo muito significativo da utilização da imagem como fonte de instrução o conjunto azulejar do Colégio Jesuíta do Espírito Santo (Universidade de Évora), datado da primeira metade do século xVIII. Sobre a utilização de imagens com fins didáticos, nomeadamente, numa perspetiva histórica, ver Rui Lopes, «A moral, mural! As ideias nos mapas e quadros parietais» (Dissertação de Doutoramento, Universidade de Lisboa, 2013).
} 
dispositivo ganha progressiva importância educacional. ${ }^{4}$ Convém, no entanto, explicitar em que aceções. Refira-se, em primeiro lugar, a imagem enquanto fonte de instrução ou recurso didático. Por exemplo, o arquiteto Edward Robert Robson, na sua obra School Architecture (1874), defende que nenhuma escola elementar pode ser considerada «well furnished» se não tiver expostos nas paredes «relief maps or charts... diagrams», os quais, de resto, devem ser periodicamente mudados. ${ }^{5}$ Por outro lado, casos há em que este fim, eminentemente instrutório, por assim dizer, é associado a postulados higienistas. Na verdade, alguns modelos de escolas primárias projetados em Portugal na década de 1880, nomeadamente, para o distrito de Santarém, incluem, na parede frontal aos alunos (nas costas, portanto, do docente), representações de mapas geográficos de «Portugal e das possessões ultramarinas», as quais tinham como duplo objetivo facilitar a aprendizagem pela memorização visual e proteger os órgãos da visão dos alunos - neste último caso, era essa a convicção, pelo facto de o olhar não incidir sobre uma superfície excessivamente branca. ${ }^{6}$ Importa, também, considerar o recurso às paredes da sala de aula para afixação de máximas e provérbios moralistas, sagrados e profanos. Por exemplo, no Dicionário Universal de Educação e Ensino (entrada «Imagens nas escolas»), menciona-se que seria muito vantajoso «estabelecer por primeira condição do ensino primário, que nas aulas estivessem colocados alguns bustos ou pendurados painéis representando as cenas da criação». ${ }^{7}$ Interessa, por fim, falar no valor das imagens para a educação estética das crianças. Trata-se de uma preocupação que emerge em alguns países da Europa entre a segunda metade do século xix e as primeiras décadas da centúria seguinte. ${ }^{8} \mathrm{~A}$ esse respeito, é expressiva a comunicação de Alexis Sluys, diretor da Escola

\footnotetext{
${ }^{4}$ Grosvenor, «"To Act on the Minds of Children"».

5 Citado em Grosvenor, "“To Act on the Minds of Children”», 41.

- Carlos Manique da Silva, Escolas Belas ou Espaços Sãos? Uma análise histórica sobre a arquitetura escolar portuguesa (1860-1920) (Lisboa: Instituto de Inovação Educacional, 2002).

${ }^{7}$ E. M. Campagne, Diccionario Universal de Educação e Ensino. Volume I (Porto: Livraria Internacional de Ernesto Chardron, 1886), 412.

${ }^{8}$ Ian Grosvenor, "To Act on the Minds of Children"»; Annie Renonciat, "The "Art at School" Movement in France. Goals, Ideas, Influence (1880-1939)», em The Decorated School. Essays on the Visual Culture of Schooling, eds. Catherine Burke, Jeremy Howard e Peter Cunningham (Londres: Black Dog Publishing, 2013), 12-18.
} 
Normal de Bruxelas, ao III Congresso de Arte Pública (Liège, 1905). Veja-se a seguinte passagem:

Il faut [...] qui les divers locaux occupés par les élèves tous les jours pendant plusieurs heures aient un aspect riant, attractif, suggestive. La décoration des murs, la forme du mobilier doivent être conçues de manière à produire des impressions de beauté [...] Il importe que tout ce qui entoure l'élève ait un caractère franchement esthétique; créons autour de lui une atmosphère de beauté. ${ }^{9}$

Não posso deixar de citar o caso francês, pelo conjunto de medidas que, desde a década de 1860, de forma sistemática, foram sendo implementadas em prol da educação estética da criança. Com efeito, em 1869, Victor Duruy, ministro da Instrução Pública, proclama a intenção de selecionar artistas que produziriam esculturas destinadas a ser utilizadas na escola (com fins educativos). ${ }^{10}$ Por outro lado, em 1880, a instâncias de Ferdinand Buisson, é instituída a Commission de la décoration des écoles et de l'imagerie scolaire. ${ }^{11}$ Em 11 de abril de 1881, num relatório da dita Comissão enviado ao ministro da Instrução Pública, Jules Ferry, é explicitamente afirmado:

Il faut que l'enfant vive entouré de nobles ouvrages qui sans cesse parlent à ses yeux, éveillent sa curiosité, élèvent son âme ; il faut que tout l'y entretienne de formes harmonieuses, l'y enveloppe de joie et de sérénité ; il faut que l'art vienne à lui pour ainsi dire de toutes parts comme l'air ambiant qu'il respire. ${ }^{12}$

A ideia de rodear a criança de obras de arte com o propósito de desenvolver a sensibilidade estética (sublinhe-se, uma questão emocional) encerra um sentido de permanência que importa explicar. Na verdade, ao contrário das imagens utilizadas como fonte de instrução ou recurso

\footnotetext{
${ }^{9}$ Alexis Sluys, «Importance de la culture esthétique dans l'éducation générale de l'enfant», em $I I I^{\mathrm{e}}$ Congrès International de l'Art Public, ed. Eugène Broerman (Bruxelles: Imp. Schaumans, 1905), 9.

10 Annie Renonciat, «The "Art at School” Movement in France».

11 Annie Renonciat, «The "Art at School” Movement in France».

${ }^{12}$ Ferdinand Buisson, Nouveau dictionnaire de pédagogie et d'instruction primaire (Paris: Edition électronique, 2004 [1911], entrada Imagerie scolaire), sem numeração. http://www.inrp.fr/edition-electronique/lodel/dictionnaire-ferdinand-buisson/document.php?id=2892. A este respeito, acresce dizer que, em 1882, o ensino do desenho passa a ser obrigatório nas escolas primárias francesas. Annie Renonciat, «The "Art at School" Movement in France».
} 
didático, as obras de arte pintadas (esculpidas ou aplicadas através de revestimentos azulejares) nas paredes da sala de aula não pressupõem substituição periódica. Com efeito, e não obstante a subjetividade do conceito de belo e a própria mudança da estética no devir histórico, as obras de arte (no contexto e no sentido a que me estou a reportar - o da educação estética da criança em meio escolar) nunca serão, para utilizar a expressão criada por Martin Lawn, "modernidades abandonadas»; ou seja, tecnologias educativas consideradas inovadoras num determinado momento, mas que, com o passar do tempo, acabam por ser relegadas.

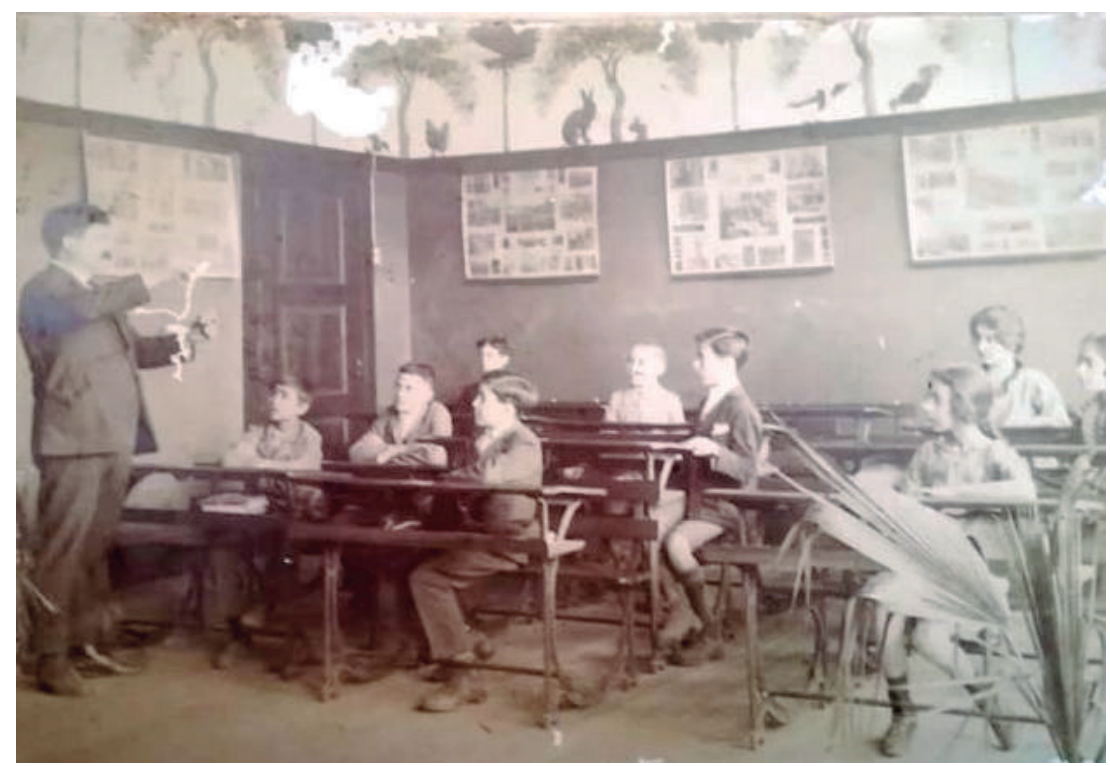

Imagem 1. Lição de geologia, $5 \cdot^{a}$ classe, na Escola Primária de Alcântara ${ }^{13}$ (início da década de 1920?). No friso observam-se pinturas da autoria de Raul Lino, representando animais e elementos da Natureza (preocupação com a educação estética); coexistem, conforme se observa, com cartazes, mapas... (recursos didáticos). ${ }^{14}$

Dito isto, no presente artigo é meu propósito perceber o impacto que as pinturas dos frisos da Escola Primária da Alcântara, na perspetiva do

\footnotetext{
${ }_{13}$ Ao longo do texto manterei, por via de regra, esta designação, embora a atual, muito justamente, seja Escola Básica Raul Lino.

${ }_{14}$ Arquivo da Escola Básica Raul Lino.
} 
seu autor (Raul Lino), teriam na mente das crianças. Para o efeito, darei atenção à influência que o movimento Arts \& Crafts teve no arquiteto, assim como aos contactos que estabeleceu com o poeta Afonso Lopes Vieira (1878-1946) e com os pedagogos João de Deus Ramos (1878-1953) e João de Barros (1881-1960), personalidades que influenciaram a sua conceção de educação estética da criança; afirmarei, ainda, a importância que a experiência autoral enquanto ilustrador de livros infantis teve na definição do programa da decoração da Escola Primária de Alcântara.

Metodologicamente importa dizer que cruzo um conjunto de fontes, designadamente, visuais (as pinturas dos frisos) e alguns textos escritos por Raul Lino (correspondência ativa e artigos). Seguindo a proposta de Sjaak Braster, ${ }^{15}$ a análise das fontes visuais parte da descrição dos elementos presentes nas pinturas (na sua maioria, animais e elementos da Natureza).

\section{RAUL LINO (1879-1974): BREVE NOTA BIOGRÁFICA}

Raul Lino nasceu em Lisboa no ano de 1879 e nessa cidade veio a falecer em 1974. O facto de ser filho de um abastado negociante de materiais de construção deu-lhe a possibilidade de estudar no estrangeiro. Em 1890, parte para Inglaterra frequentando aí um colégio católico nos arredores de Windsor. Aí permanece durante três anos, rumando depois à Alemanha com o objetivo de estudar a língua e de cursar arquitetura. Dessa experiência, Raul Lino destaca, sobretudo, os ensinamentos do professor Albrecht Haupt, em cujo ateliê trabalhou em regime de voluntariado durante dois anos. Não se estranha, assim, serem evidentes na sua obra, por um lado, os reflexos do movimento Arts \& Crafts, criado em Inglaterra na segunda metade do século XIX por John Ruskin (1819-1900) e concretizado por William Morris (18341896); e, por outro lado, do Deutscher Werkbund, agremiação artística fundada na Alemanha, em 1907, mas cujos princípios estavam já em debate no final do século XIX. ${ }^{16}$

\footnotetext{
${ }^{15}$ Sjaak Braster, «Educational change and dutch classroom photographs. A qualitative and quantitative analysis», em The Black Box of Schooling. A Cultural History of the Classroom, eds. Sjaak Braster, Ian Grosvenor e María del Mar del Pozo Andrés (Bruxelas: Peter Lang, 2011), 21-37.

16 José Manuel Fernandes, «Olhando a obra de Raul Lino, a pensar em Frank Lloyd Wright: partindo do Arts \& Crafts, com a Natureza, o Orgânico e a Casa», Pós 23, no. 40 (2016): 168-189.
} 
Em 1897 está de regresso a Portugal, completando o seu curso livre de Arquitetura (o diploma oficial de arquiteto ser-lhe-á conferido em 1926) e começando a trabalhar nas oficinas do pai. Datam de finais do século XIX os primeiros trabalhos de arquitetura e as viagens pelo país, em particular pelo Alentejo, no decurso das quais recolhe diversos elementos sobre arquitetura tradicional. De resto, o projeto apresentado em 1899 para o Pavilhão de Portugal na Exposição Nacional de Paris, de 1900, afirma-se em contraponto à influência das beaux-arts, inspirado «em estilos portugueses de várias épocas, combinados numa composição verosímil e bastante harmoniosa». ${ }^{17}$ Numa abordagem que se prende a valores nacionais, Raul Lino procurou, aliás, encontrar uma definição de "Casa Portuguesa» que traduzisse as maneiras de ser e de estar portuguesas, recuando para o efeito à matriz arquitetónica do século Xvi. Linha de pensamento que influenciará decisivamente a sua obra, materializada, por exemplo, na utilização do alpendre, no recurso aos revestimentos azulejares e, mesmo, no emprego de materiais típicos de cada região.

Autor de mais de 700 projetos arquitetónicos, Raul Lino desenvolveu a sua atividade profissional liberal em acumulação com cargos na administração pública, designadamente na Direção-Geral dos Edifícios e Monumentos Nacionais. Entre as suas obras de referência contam-se a Casa dos Patudos (Alpiarça, 1904), a Casa do Cipreste (Sintra, 1912), o cinema Tivoli (Lisboa, 1925) e o Pavilhão do Brasil na Exposição do Mundo Português (1940). Concebeu, igualmente, vários modelos de edifícios escolares, alguns deles projetos-tipo oficiais. ${ }^{18}$

Curiosamente, ao longo da vida, Raul Lino foi também desenvolvendo áreas como a azulejaria, os vitrais e o mobiliário, revelando, assim, uma grande versatilidade e a vontade de integrar a arte em todas as manifestações da vida humana - na linha, de resto, de uma personalidade

\footnotetext{
${ }_{17}$ Raul Lino, «Raul Lino visto por ele próprio», Vida Mundial (Lisboa), no 1589, 21 de novembro de 1969, 29.

${ }_{18}$ Carlos Manique da Silva, «Escolas, Higiene e Pedagogia: espaços desenhados para o ensino em Portugal (1860-1920)», em Educação e património cultural: Escolas, objetos e práticas, coord. Maria João Mogarro (Lisboa: Edições Colibri/ Instituto de Educação, 2013), 93-117; Carlos Manique da Silva, «Raul Lino, protagonista de uma mudança na arquitetura escolar durante a I República Portuguesa», Educar em Revista 49 (2013): 83-102.
} 
como William Morris. ${ }^{19}$ Foi ainda autor de estudos teóricos, como A Nossa Casa (1918), A Casa Portuguesa (1929), Casas Portuguesas (1933) e L'Évolution de l'architecture domestique au Portugal (1937), influenciado pelas obras de Baillie Scott, Hermann Muthesius e dos irmãos Fletchter. ${ }^{20}$

\section{CONTACTO COM PEDAGOGOS/ MOVIMENTOS PEDAGÓGICOS E «APROXIMAÇÃO» À LITERATURA INFANTIL}

Raul Lino foi um arquiteto muito sensível às questões educativas, particularmente à condição da infância. Essa preocupação é manifestada na segunda década do século xx, num momento histórico de «redescoberta da criança», para adotar a expressão de António Nóvoa. ${ }^{21}$ Veja-se, por exemplo, que no último quartel do século xix Raul Lino tomou contato com o movimento pedagógico que João de Deus (1830-1896) promoveu em prol da educação de infância. Com efeito, seguindo as orientações pedagógicas do filho deste, João de Deus Ramos, desenhou o projeto-tipo de jardim-escola que viria a ser materializado entre 1911 e a década de 1950, sob tutela da Associação de Escolas João de Deus. Em 1908, Raul Lino manifestara inteira disponibilidade e vontade de abraçar o referido projeto, conforme transmite a João de Deus Ramos, em missiva datada de 2 de janeiro. No texto é patente a filiação pedagógica e artística que presidiria ao programa arquitetónico:

Tem esta unicamente por fim confirmar o que declarei hoje verbalmente a $\mathrm{V} . \mathrm{Ex}^{\mathrm{a}}$. com respeito ao projeto arquitetónico para a escola-modelo em Coimbra - estou completamente ao dispor de V. Ex . para elaborar este projeto que muito me interessará e sinto-me feliz por poder colaborar [...]. Depois de ouvir as explicações de V. Ex ${ }^{a}$. estou certo que me dedicarei com entusiasmo a este trabalho que por ser inspirado nas teorias de Tolstoi deve também obedecer a Ruskin na parte artística. ${ }^{22}$

\footnotetext{
19 José Manuel Fernandes, «Olhando a obra de Raul Lino».

${ }^{20}$ Carla Garrido de Oliveira, «De “A Nossa Casa” a “Casas Portuguesas”: Raul Lino entre livros, entre tempos, entre modos, entre modernos europeus», em Celebrando a Nossa Casa (1918-2018) de Raul Lino. Antologia de Ensaios, coord. Paula André (Lisboa: ISCTE, 2018), 151-169.

${ }^{21}$ António Nóvoa, Evidentemente. Histórias da Educação (Porto: Edições ASA, 2005), 89.

22 Citado por Elsa Rodrigues, «Jardim-Escola João de Deus (Lisboa-Estrela)», em Roteiros da Inovação Pedagógica. Escolas e experiências de referência em Portugal no século xx, coord. Joaquim
} 
Acresce dizer que Raul Lino teve interlocução privilegiada com João de Barros, político e educador republicano defensor das escolas móveis pelo método João de Deus. ${ }^{23}$ Tratou-se, aliás, de uma relação de amizade que acabaria por traduzir a identidade de pontos de vista entre as duas personalidades, nomeadamente, sobre educação. A verdade é que, nessa matéria, o arquiteto colheu muito desse relacionamento. Tenhamos em mente que João de Barros participou, em 1907, numa missão oficial com fins pedagógicos, visitando então, acompanhado por João de Deus Ramos, várias instituições escolares em quatro países da Europa (Espanha, França, Inglaterra e Bélgica). Com toda a probabilidade tomou conhecimento do nascimento em Paris, precisamente no referido ano, da Sociedade «L'Art à l'École». ${ }^{24}$ Promovida por personalidades de renome (Ferdinand Buisson, Georges Moreau, Léon Riotor, para citar apenas algumas), apoiada pelo Estado francês e granjeando importante projeção (nacional e internacional), o escopo da referida associação era o de facultar a educação estética nas escolas. ${ }^{25}$ Certo é que João de Barros é particularmente sensível ao tópico da educação estética da criança, conforme expressa no relatório que publicou sobre a mencionada missão pedagógica. Atente-se, por exemplo, na seguinte passagem, que se reporta ao Colégio de Bedales, em Petersfield (Inglaterra):

Pintassilgo e Luís Alberto Marques Alves (Lisboa: Instituto de Educação da Universidade de Lisboa, 2019), 206. Mais tarde, isto é, na segunda metade da década de 1920, Raul Lino e João de Deus Ramos voltarão a estabelecer nova parceria, nomeadamente, no âmbito da construção do Bairro Escolar do Estoril. A este respeito, consulte-se Manuel Henrique Figueira, Um Roteiro da Educação Nova em Portugal (Lisboa: Livros Horizonte, 2004).

${ }_{23}$ António Nóvoa (dir.), Dicionário de Educadores Portugueses (Porto: Edições ASA, 2003).

${ }_{24}$ Annie Renonciat, «The "Art at School” Movement in France». A propósito, acresce dizer que, em finais do século XIX, surgem as primeiras sociedades preocupadas com a promoção da arte na escola, nomeadamente, na Suécia, Bélgica e Inglaterra. A este respeito, consulte-se Henry Baudin, Les Constructions Scolaires en Suisse (Genève: Editions d'Art \& d'Architecture, 1907). Acresce dizer que, em Espanha, nas décadas de 1920 e 1930, Pedro Chico, catedrático de Geografia de Escolas Normais, defenderá a criação, em todas as províncias, de Sociedades de Amigos del Arte en la Escuela. Sobre o assunto, ver Pedro Chico, Decoración Escolar (Madrid: Publicaciones de la Revista, de Pedagogia,

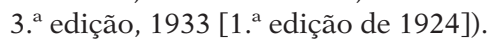

${ }_{25}$ Annie Renonciat, «The "Art at School” Movement in France». A mesma autora refere como importante precedente da criação da Sociedade L'Art à l'École, a realização em Paris, corria o ano de 1904, de uma conferência e exposição subordinadas ao tema «A Arte na Escola». O lema da referida Sociedade era o seguinte: «Fazer amar a criança a natureza e a arte; tornar a escola atraente». Sobre o assunto, ver Adolfo Lima, «Educação e ensino. Exposição de Arte na Escola», Germinal 5 (1916): 146-151. 
A arquitetura desta [escola], sóbria e elegante, as musselinas claras das janelas, as trepadeiras floridas que enfeitam as paredes, tudo isso, junto com o ar fresco e saudável dos petizes, dános logo uma ótima impressão de alegria, de infância livre, livremente desenvolvendo as suas aptidões num meio carinhoso e acolhedor. $^{26}$

De resto, a sua ideia do que deveria ser o edifício escolar (num sentido mais lato, o ambiente escolar) é lapidarmente expressa na frase que se transcreve: "se essa escola [ideal] for decorada com o preciso gosto, senão com arte, realizaremos assim algumas das condições indispensáveis para a felicidade, para a alegria da criança». ${ }^{27}$ Aquilo que me parece importante sublinhar é que o debate estabelecido entre João de Barros e Raul Lino acabou por fazer cruzar diversas influências: no caso da primeira personalidade, emerge o conhecimento da realidade pedagógica de países tão diferentes como França, Espanha, Inglaterra (sem esquecer, de modo óbvio, Portugal); na circunstância da segunda personalidade, sobressai a formação artística de matriz germânica e anglo-saxónica. É evidente, acresce ainda dizer, que uma personalidade como João de Deus Ramos, que conhecia bem a realidade educativa extrafronteiras, inclusivamente a pedagogia de Froëbel, Pestalozzi, Decroly e Maria Montessori ${ }^{28}$ - não faltando, conforme vimos, referências a Tolstoi -, teve, também, influência no pensamento pedagógico do arquiteto.

Por outro lado, em 1912, Raul Lino surge associado à promoção de um programa para a infância da autoria do poeta Afonso Lopes Vieira (responsável por trabalhos de literatura para a infância e juventude, entre outros). Com efeito, em 4 de fevereiro do referido ano era publicado no jornal $A$ Capital um artigo intitulado "As nossas crianças». O texto de Lopes Vieira, radical em algumas passagens - o poeta chega mesmo a propor a inutilização de todas as escolas do Estado (a generalidade encontrava-se em péssimas condições), construindo-se em sua substituição novos edifícios, sendo ademais necessário decorá-los -, é ilustrado com um desenho inédito de Raul Lino representando uma escola primária. Essa colaboração, no entanto, remontava ao ano anterior, no

\footnotetext{
${ }^{26}$ João de Barros, A Escola e o Futuro (Porto: Livraria Portuense de Lopes \& C. ${ }^{a}$ Sucessor, 1908$), 78$.

27 João de Barros, A Escola e o Futuro, 137.

${ }_{28}$ Elsa Rodrigues, «Jardim-Escola João de Deus (Lisboa-Estrela)».
} 
momento exato em que o arquiteto ilustrara a obra Animais nossos amigos, dirigida a um público infantil; tarefa (de coautoria, em bom rigor) que prosseguiria nas décadas seguintes, merecendo especial destaque a ilustração do livro, também de Lopes Vieira, Bartolomeu Marinheiro (1912), escrito para um público juvenil. ${ }^{29}$

Ora, a referida faceta de Raul Lino (a de ilustrador de livros infantojuvenis) traduz bem a sua preocupação com a condição da infância e da juventude, particularmente, o compromisso social de a tornar mais feliz e sensível a determinados estímulos (algo que, do seu ponto de vista, passaria obrigatoriamente pela educação estética). De resto, conforme veremos, é muito interessante que o programa decorativo da Escola Primária de Alcântara integre a experiência de Raul Lino enquanto ilustrador da obra Animais nossos amigos.

\section{RAUL LINO: QUE ENTENDIMENTO DE EDUCAÇÃO ESTÉTICA DA CRIANÇA?}

Ao longo de várias décadas da sua carreira, Raul Lino demonstrou especial interesse pelo tema da educação estética da criança. Com efeito, além do pensamento pontualmente expresso em memórias descritivas de projetos de escolas, produziu trabalhos nos quais abordou especificamente o referido tema (associado à decoração das escolas primárias). Para o meu objeto de estudo, merece especial atenção o título Considerações sobre a estética nas escolas, publicado em 1916. ${ }^{30}$ Uma das premissas fundamentais para o arquiteto é a de que as decorações escolares devem ser simples e agradar às crianças. ${ }^{31}$ Para ilustrar essa

\footnotetext{
${ }^{29}$ Sobre a atividade de Raul Lino enquanto ilustrador de livros infantis e juvenis, consulte-se o catálogo Raul Lino: exposição retrospectiva da sua obra (Lisboa: Fundação Calouste Gulbenkian, 1970) e Cristina Nobre, Afonso Lopes Vieira: a reescrita de Portugal (Lisboa: Imprensa Nacional-Casa da Moeda, 2005).

${ }^{30}$ Este trabalho, elaborado a pedido da Sociedade de Estudos Pedagógicos, é muito similar ao que Raul Lino publicou, no mesmo ano, no Boletim Oficial do Ministério de Instrução Pública, a respeito da decoração da Escola Primária de Alcântara; o qual seguirei, por se reportar ao objeto do presente estudo. Em meados da década de 1950, o arquiteto voltará a abordar, especificamente, o tema da educação estética da criança. Sobre o assunto, ver Raul Lino, «Decorações educativas e artísticas nas escolas primárias», Revista Municipal 67 (1955): 30-33. Interessa, ainda, mencionar que Raul Lino participou na Exposição de Arte na Escola, em 1916, cuja organização esteve a cargo da Sociedade de Estudos Pedagógicos.

${ }^{31}$ Raul Lino, «Decoração de Escolas Primárias. Memória Justificativa de uma Proposta para a Decoração da Escola de Alcântara», Boletim Oficial do Ministério de Instrução Pública 3 (1916): 191-194.
} 
ideia, estabelece paralelo com a música, a qual, na sua perspetiva, tem valor educativo sem transmitir noções concretas.32 Dirá, a propósito, que não se deve exigir que as «decorações façam mais do que despertar nas crianças o sentimento do belo como ele se nos revela na natureza»;33 assim, o intuito é o de estimular sentimentos «de ordem, ritmo e harmonia». ${ }^{34}$ Ora, esta ideia - da obra de arte como «elemento educativo do gosto", conforme apelidará mais tarde ${ }^{35}$-, é contrária à utilização da decoração para ilustrar máximas ou conceitos, os quais «as crianças depressa se habituam a encarar sem a mínima comoção».36 É muito interessante, de resto, e consistente com as ideias que têm vindo a ser expressas, que Raul Lino desaconselhe a inclusão de painéis com assuntos descritivos no interior da sala de aula; dessa forma, segundo indica, haveria o risco de os alunos se distraírem nos estudos. ${ }^{37}$ No fundo, reconhecendo que "há muitas moralidades a ensinar às crianças», o processo artístico serviria "para a transmissão de sensações sugestivas ou de simples estímulo». ${ }^{38}$ Nesse processo, a Natureza tem particular relevância, na medida em que se constitui como um referente ético e moral na formação da criança - o arquiteto sublinhará, amiúde, a necessidade de as decorações artísticas despertarem «o encanto de certas maravilhas da natureza». ${ }^{39}$ Em causa, o papel moral e social da arte, na linha, aliás, das convicções de John Ruskin e William Morris. ${ }^{40}$

Importa dizer que o foco na Natureza não pode ser dissociado da afirmação das obras de Raul Lino no quadro de um movimento de

\footnotetext{
32 Raul Lino, «Decoração de Escolas Primárias».

33 Raul Lino, «Decoração de Escolas Primárias»: 194. Ideia muito próxima havia já sido defendida por Alexis Sluys, em 1905, no Congresso Internacional de Arte Pública (Liège), ao sustentar que a educação estética da criança teria de passar pelo contacto direto com a Natureza e os objetos de arte, os quais, aliás, se inspirariam na primeira. Alexis Sluys, "Importance de la culture esthétique dans l'éducation générale de l'enfant».

34 Raul Lino, «Decoração de Escolas Primárias»: 194.

35 Raul Lino, «Decorações educativas e artísticas nas escolas primárias»: 32.

36 Raul Lino, «Decoração de Escolas Primárias»: 191.

37 Raul Lino, «Decoração de Escolas Primárias».

38 Raul Lino, «Decoração de Escolas Primárias»: 191.

39 Raul Lino, «Decoração de Escolas Primárias»: 193.

40 Annie Renonciat, "The "Art at School” Movement in France». Segundo a autora, Ruskin e Morris defendiam a educação artística e estética para todos.
} 
reação estética e artística já aqui mencionado: o Arts \& Crafts. Trata-se de uma reação ao crescente processo de industrialização na Inglaterra do século XIX. ${ }^{41}$ Uma das ideias centrais desse movimento, aprofundado por William Morris, assenta na valorização do trabalho artesanal criativo e das artes decorativas; ${ }^{42}$ recusa clara da mecanização e da produção industrial em massa. Desse ponto de vista, importava recuperar "a pureza idealizada da vida e da época pré-máquina».43 A essa luz, e também por via da influência do Romantismo, se deve entender a valorização e o culto da Natureza. De resto, com a mesma orientação se afirma na Alemanha no início do século xx o movimento Deutscher Werkbund, cujo ideal se baseava na recuperação de uma harmonia considerada perdida. ${ }^{44}$

É, de facto, no universo dos dois citados movimentos, particularmente, o Arts \& Crafts, que deve ser entendida a produção artística de Raul Lino (relembre-se a sua formação em Inglaterra e na Alemanha). Uma ideia chave é a de oposição ao progresso industrial e de valorização do trabalho artesanal e das artes decorativas. Este ponto é importante, na medida em que permite diferenciar as propostas de educação estética de Raul Lino da afirmação contemporânea de outro movimento que pugna pela integração da arte na escola. Refiro-me às ideias veiculadas pela Sociedade L'Art à l'École, fundada em Paris, no ano 1907, e já aqui mencionada. Com efeito, e não obstante ter como objetivos «to help children love nature and art, to make the school more attractive, to educate chidren's taste», a verdade é que a dita Sociedade se enquadra num movimento que se distancia das teses de Ruskin e Morris, justamente, por os seus promotores não recusarem o progresso industrial. 45

É a luz do Arts \& Crafts que me interessa prosseguir a análise do pensamento de Raul Lino, particularmente a ideia, filiada no dito movimento,

\footnotetext{
${ }^{41}$ José Manuel Fernandes, «Olhando a obra de Raul Lino».

42 José Manuel Fernandes, «Olhando a obra de Raul Lino»; Maria do Carmo Pimenta de Vasconcelos e Sousa Lino, "As artes decorativas na obra de Raul Lino» (Dissertação de mestrado, Universidade Lusíada, 1999).

43 José Manuel Fernandes, «Olhando a obra de Raul Lino»: 172.

${ }_{44}$ José Manuel Fernandes, «Olhando a obra de Raul Lino». Acresce, ainda, dizer que a obra de Raul Lino em questão se produz no período histórico em que estão prestes a eclodir outros movimentos, nomeadamente, a Bauhaus e o muralismo como expressão artística.
}

45 Annie Renonciat, «The "Art at School" Movement in France», 14. 
de que os edifícios devem proporcionar alegria e conforto aos seus utilizadores; este último atributo deve ser entendido como qualidade espiritual. ${ }^{46}$ Com efeito, os projetos decorativos para as escolas primárias assinados por Raul Lino, além de procurarem levar a arte à criança (no sentido já expresso, ou seja, de educar o gosto), visam, especialmente, criar um ambiente confortável e alegre. Este pensamento é bem elucidado pelo arquiteto em carta-depoimento a João de Barros, a propósito da Escola Primária de Alcântara:

Uma ingénua decoração enxaquetada de azulejo chama a atenção do enxame estudioso para a entrada do seu cortiço, e esta em si é formada por um largo e baixo arco, feito menos para impor respeito às crianças do que para engolir sofregamente o turbilhão gargalhante de rapazes e raparigas. ${ }^{47}$

Ora, é atendendo aos pressupostos anunciados - se quisermos, a uma relação entre arte e observador que tem em linha de conta a sensibilidade e a compreensão estética da criança (posta, de facto, no centro desse processo de aprendizagem) - que irei agora abordar o programa decorativo da Escola Primária de Alcântara.

\section{O PROGRAMA DECORATIVO DA ESCOLA PRIMÁRIA DE ALCÂNTARA}

Inaugurado em 1916, o edifício da Escola Primária de Alcântara foi concebido para 800 alunos (funcionaria em dois turnos, em regime de coeducação). Não deixa de ser curioso a iniciativa ter partido do Estado, uma vez que, no ano de 1915 (data em que o projeto foi elaborado), estávamos em pleno período de descentralização do ensino.

Quanto à planta do edifício, verifica-se que, para além de dez salas de aula (cinco em cada piso), o arquiteto optou por desenhar uma cantina no rés-do-chão, bem como, no espaço homólogo do andar superior, uma sala de leitura intercomunicando com uma sala de aula. Nesse mesmo pavimento consagrou a existência de um espaço reservado a museu.

\footnotetext{
46 José Manuel Fernandes, «Olhando a obra de Raul Lino».

47 João de Barros, «Edifícios escolares de Raul Lino», Atlântida 4 (1916): 335.
} 
Por outro lado, no exterior, Raul Lino seguiu o princípio «intimista».48 Ou seja, valorizou a integração do edifício num parque botânico da cidade de Lisboa (Tapada da Ajuda), criando, desse modo, um efeito de isolamento numa zona da cidade (bairro de Alcântara) em franco desenvolvimento industrial desde a segunda metade do século XIX.

Interessa precisar que na Escola Primária de Alcântara - noto que, passados mais de cem anos, o edifício continua a cumprir o fim para o qual foi concebido - existem dois programas decorativos claramente diferenciados: i) o de autoria de Raul Lino (no essencial, circunscrito às salas de aulas e ao átrio), datado de 1917 e que contou com a colaboração de outros artistas;49 ii) e o que foi assinado pelo pintor António Soares, em 1918, subordinado ao tema "A indústria de Alcântara» e que preenche o friso do corredor do piso térreo. Não obstante a minha análise ter como foco o primeiro programa citado, não posso, no entanto, deixar de assinalar a importância da composição da responsabilidade de António Soares (mestre convidado por Raul Lino, tudo leva a crer), assim como a sua coerência no conjunto de toda a obra decorativa. Com efeito, estando a Escola implantada numa zona industrial, não surpreende a temática. Em meu entender, as imagens, poderosas pela ilustração da dureza das condições laborais, pretendiam promover a dignidade do trabalho manual, num momento, por paradoxal que possa parecer, de rápida industrialização. Linha de pensamento, recorde-se, em sintonia com as ideias de Raul Lino, filiadas no movimento Arts \& Crafts. Mais, a própria inserção da composição de António Soares no local indicado (friso do corredor) é coerente com o pensamento do arquiteto. Ou seja, conforme se afirmou na secção anterior, assuntos descritivos não deveriam figurar nas salas de aula, uma vez que poderiam distrair os alunos dos estudos. Acresce referir que Raul Lino defendia a existência de painéis com assuntos descritivos «inspirados, de preferência, na história política ou etnografia da região». ${ }^{50}$ Mas, do seu ponto de vista, tal tarefa teria sempre de ser executada pelas mãos de mestres. ${ }^{51}$

\footnotetext{
48 José Manuel Fernandes, «Olhando a obra de Raul Lino».

49 A este respeito, consulte-se Inventário do Património Arquitetónico, do IHRU, IPA.00006105.

50 Raul Lino, «Decoração de Escolas Primárias»: 193.

51 Raul Lino, «Decoração de Escolas Primárias».
} 


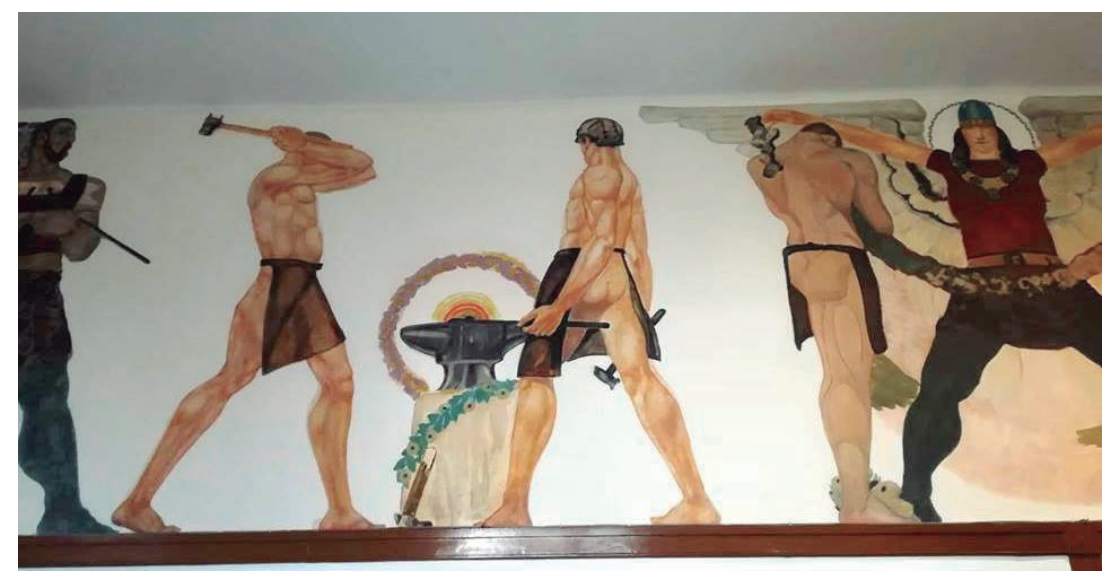

Imagem 2. Trecho da composição "A indústria de Alcântara», da autoria de António Soares, 1918. Friso do corredor térreo da Escola Primária de Alcântara. ${ }^{52}$

Contrastante com a composição de António Soares é a decoração do interior das salas de aula e do átrio. Neste caso, sobretudo nas salas de aula, o propósito da decoração, pródiga em motivos bucólicos e representações de animais, flores e plantas, era o de agradar à criança, fomentando o amor pela Natureza e pelo belo, educando, no fundo, o gosto verdadeiro programa de educação estética. Em causa, para Raul Lino, a ideia de que as imagens (obrigatoriamente, simples e sugestivas) despertariam a sensibilidade estética da criança.

Mas, antes de me centrar na decoração das salas de aula julgo útil tecer breves considerações sobre a ornamentação do átrio. Uma vez mais, emerge a coerência do pensamento de Raul Lino. Com efeito, o arquiteto, no texto que publicou a respeito da decoração da Escola Primária de Alcântara, defendeu a importância de, nos átrios e paredes de escadas, existirem motivos heráldicos de grande dimensão, outros ligados aos Descobrimentos (nomeadamente, caravelas), sem esquecer a reprodução dos versos iniciais do hino nacional. ${ }^{53}$

No friso do átrio, aquilo que se observa, a par, por exemplo, da pintura das armas da cidade de Lisboa, do escudo de armas português e de diversas

\footnotetext{
52 Foto do autor, maio de 2019.

53 Raul Lino, «Decoração de Escolas Primárias».
} 
flâmulas coloridas, é a representação, no teto desse mesmo espaço, de um enorme papagaio de papel; nota ridente, de convite à entrada num ambiente que se pretendia agradável e que suscitasse a curiosidade da criança.

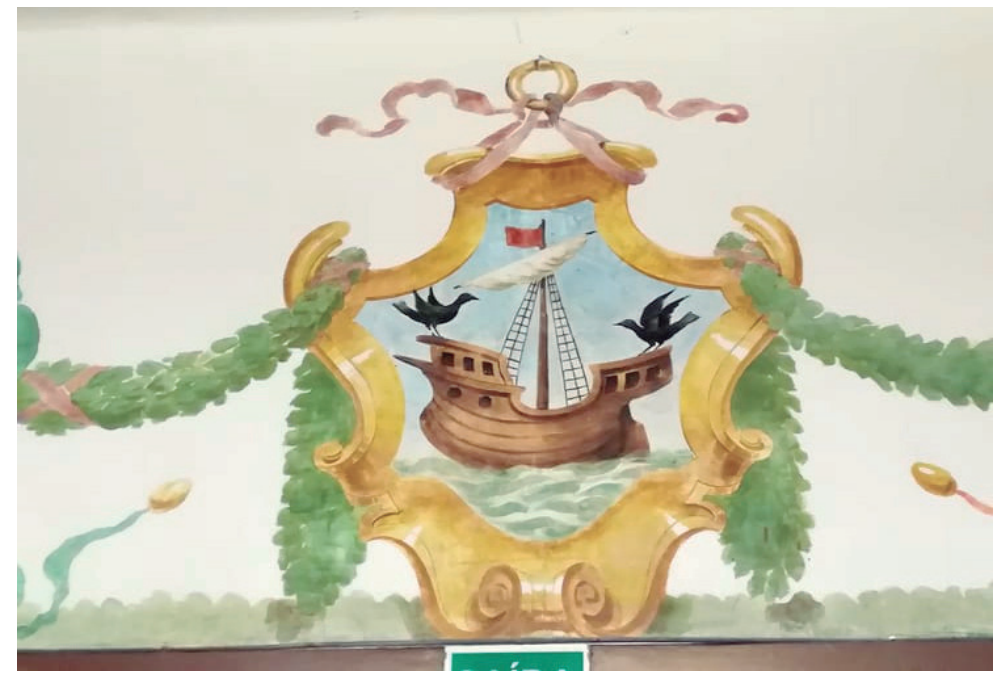

Imagem 3. Pormenor das armas de Lisboa, friso do átrio da Escola Primária Alcântara. ${ }^{54}$

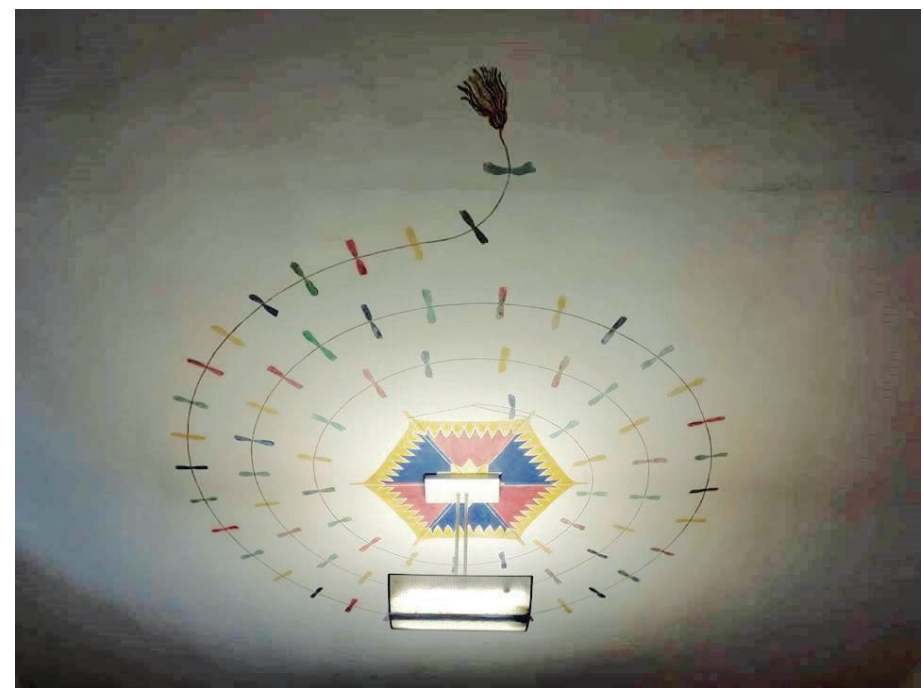

Imagem 4. Representação de papagaio de papel, teto do átrio da Escola Primária de Alcântara. ${ }^{55}$

\footnotetext{
${ }^{54}$ Foto do autor, maio de 2019.

55 Foto do autor, maio de 2019.
} 
Passando a analisar a decoração dos frisos das salas de aula - pintada por Raul Lino e mestres colaboradores (Fred Abecassis, Conceição da Silva e Alice Rey Colaço), ${ }^{56}$ em 1917 -, interessa, em primeiro lugar, perceber a filiação ou a fonte de inspiração do programa. Mencionei, ainda que genericamente, que a decoração dos frisos é composta por motivos bucólicos e representações de animais, flores e plantas, também alguns elementos regionais. A matriz dessas representações é, tudo leva a crer, o já citado livro do poeta Afonso Lopes Vieira, Animais nossos amigos, dado à estampa em 1911. Há, na verdade, uma fonte que estabelece ligação entre essa obra e um programa de decoração de escolas primárias. Refiro-me a um texto de Afonso Lopes Vieira, também já citado, publicado no periódico A Capital, em 1912, com o título «As nossas crianças». A dada passagem, relacionada com a oferta da mencionada obra ao presidente da República, explica Lopes Vieira:

Quando Raul Lino e eu saímos do palácio [de Belém], pensávamos ambos, com grande tristeza, na grande alegria com que, meses antes, ele desenhara todos[?] os projetos de escolas primárias, pequenos casais floridos e risonhos, gaiolas abertas onde os ledos passarinhos se sentissem voluntários prisioneiros da lição; e com que eu, por minha humilde parte, escrevera os versos dos Animais, que o meu colaborador [Raul Lino] ia ilustrando; e com que, também, ideara a decoração dessas escolas. ${ }^{57}$

Ora, essas mesmas ilustrações influenciaram a decoração dos jardins de infância João de Deus, cujo projeto-tipo, como se disse, foi da responsabilidade de Raul Lino. ${ }^{58}$ João de Barros, aludindo ao primeiro Jardim-Escola João de Deus (inaugurado em Coimbra, no ano de 1911), exalta as qualidades do arquiteto, nomeadamente, o facto de «não copiar dos modelos estrangeiros o tipo de casa e a decoração das paredes»;59 e adianta que «tudo foi delineado, executado e acabado por artistas portugueses, e inspirado, o edifício, na nossa arquitetura provinciana». ${ }^{60} \mathrm{Em}$ consequência, conforme

\footnotetext{
56 A este respeito, consulte-se Inventário do Património Arquitetónico, do IHRU, IPA.00006105.

57 Afonso Lopes Vieira, «As nossas crianças», A Capital (Lisboa), 4 de fevereiro de 1912, sem numeração.

${ }_{58}$ No Museu Pedagógico João de Deus, em Lisboa, está exposto um conjunto de aguarelas da autoria de Raul Lino, realizado em 1911, que tem muitas similitudes com algumas ilustrações da obra Animais nossos amigos.

59 João de Barros, A República e a Escola (Lisboa: Aillaud, 1920), 90.

60 João de Barros, A República e a Escola, 90.
} 
expressa, a «arte do nosso portuguesíssimo Raul Lino ali [no Jardim] triunfa». ${ }^{61}$ Por outro lado, aquilo que também interessa destacar é a opinião de João de Barros (não divergente da de Raul Lino) sobre aquilo que deveria ser o espaço escolar. Diz então, na referência ao Jardim-Escola de Coimbra (em linha, de resto, com as teses que defendera no já citado relatório de 1908):

Acolhe bem as crianças, cujos olhos ávidos são logo atraídos pelas decorações murais, primeira lição de educação estética, primeiro balbucio de ensino patriótico, fixando em formas e atitudes amoráveis a graça, o encanto e a utilidade dos nossos animais domésticos. ${ }^{62}$

É também esse, em boa medida, o sentido programático da decoração dos frisos das salas de aula da Escola Primária de Alcântara. ${ }^{63} \mathrm{Na}$ verdade, a ideia que emerge do conjunto é a de exaltação da Natureza e dos animais domésticos (entre outros). Veja-se que a obra Animais nossos amigos faz, justamente, a apologia de alguns animais (o cão, o gato, o lobo, os pássaros, os sapos, os bois, as abelhas e os burros), realçando as suas qualidades.

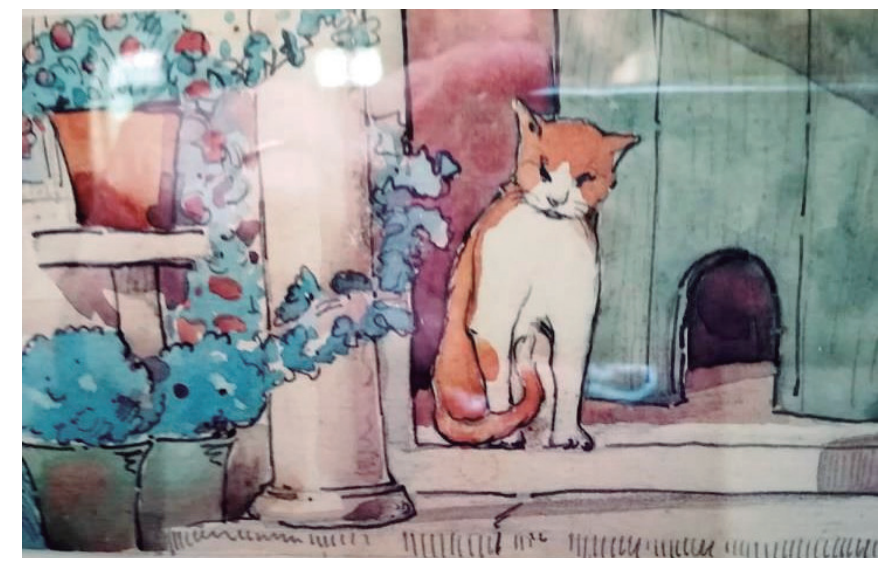

Imagem 5. Aguarela de Raul Lino, 1911. Museu Pedagógico João de Deus.

Estudo para a obra Animais nossos amigos (?).64

\footnotetext{
${ }^{61}$ João de Barros, A República e a Escola, 90.

62 João de Barros, A República e a Escola, 90.

${ }_{63}$ A propósito, alguns autores destacam a importância dos frisos na decoração escolar, designadamente, pelo seu valor pedagógico. Pedro Chico, por exemplo, chega mesmo a sugerir aos docentes alguns temas: fábulas; silhuetas de animais; cenas da vida agrícola; fábricas, ofícios e profissões; cenas infantis; cenas e personagens da história de Espanha, entre muitos outros. Pedro Chico, Decoración Escolar.

${ }^{64}$ Foto do autor, junho de 2019.
} 
Ora, aquilo que me interessa sublinhar é que nos frisos da Escola Primária de Alcântara se celebram também vários animais (alguns deles coincidentes com os da obra Animais nossos amigos). Em meu entender, Raul Lino transportou e integrou a experiência autoral de 1911 no programa decorativo da referida Escola. ${ }^{65} \mathrm{O}$ sentido desta afirmação deve ficar bem explícito. Para o efeito, julgo importantes os comentários que Virgínia de Castro e Almeida teceu, em 1912, a respeito do livro Animais nossos amigos. De facto, a autora destaca, por um lado, a ideia de que a obra em causa representa uma "parcela [de] aperfeiçoamento moral» para as crianças; e, por outro lado, enfatiza a condição de coautor do arquiteto, ou seja, a de que as ilustrações de Raul Lino «são o complemento natural da obra; inspiram-se na mesma ideia».66 $\mathrm{O}$ pressuposto, no fundo, é o de que a Natureza (num sentido lato) se constitui como um referente ético e moral na formação da criança. E é, sobretudo, este argumento que me interessa revelar, mais do que encontrar aspetos visuais e formais coincidentes entre as ilustrações do livro Animais nossos amigos e a decoração dos frisos da Escola Primária de Alcântara.

Conforme afirmei, é particularmente a devoção à Natureza e a atenção a aspetos e diferenciação regionais que estão plasmados na decoração dos frisos das dez salas de aula da Escola Primária de Alcântara. A ideia, para o arquiteto, «era desenvolver na criança o sentimento daquela beleza que lhe é mais acessível no estado de formação do seu pequeno cérebro», 67 adiantando que, para os «frisos das classes, convêm [...] motivos de um efeito alegre mas sossegado».68 Percebe-se, em consonância, que espaços da Escola Primária de Alcântara com uma orientação funcional muito específica ficassem desprovidos de decoração. Falo, nomeadamente, do museu, que tinha uma vocação presentista (lições de coisas), e da sala de leitura (biblioteca) - importava, recorde-se, não desviar o foco.

Não obstante o sentido global que o programa decorativo encerra, não deixa, ao mesmo tempo, de se individualizar em cada uma das salas de aula. Questão importante é a de perceber em função de que critério(s)

\footnotetext{
65 Sobre a integração das artes na obra do arquiteto, ver Carla Garrido de Oliveira, «De "A Nossa Casa" a "Casas Portuguesas"».

${ }^{66}$ Citado em Cristina Nobre, Afonso Lopes Vieira: a reescrita de Portugal, 509.

67 Raul Lino, «Decoração de Escolas Primárias»: 192.

68 Raul Lino, «Decoração de Escolas Primárias»: 193.
} 
foi pensada a decoração de cada um desses espaços, sabendo-se, à partida, que o arquiteto valorizava a relação orgânica entre o projeto e os utilizadores. Por exemplo, embora não possua quaisquer informações sobre a organização pedagógica primitiva, seria muito interessante saber se os motivos decorativos foram concebidos tendo em conta a distribuição das classes (o mesmo é dizer, considerando a idade dos alunos, dado tratar-se de uma escola graduada).

Aquilo que vou procurar fazer agora, sem ser exaustivo, é uma interpretação dos elementos decorativos presentes nos frisos das salas de aula, seguindo, para o efeito, a seguinte metodologia, inspirada em Braster: ${ }^{99}$ i) descrever o que se vê (e não se vê); ii) explicar o que se vê (e não se vê); iii) formular hipóteses sobre o que se vê (e não se vê). ${ }^{70}$

Uma leitura geral permite afirmar o seguinte: em quase todas as salas de aula se combinam elementos decorativos vegetais e animais (em apenas uma delas se foge a esta regra, não sendo representados animais). Do mesmo modo, em praticamente todas as salas de aula são marcantes as ornamentações populares, nomeadamente: os ramalhetes de flores; os caniçados que amparam cravos em vasos; as guirlandas; os arcos a lembrar os arranjos de arraiais.

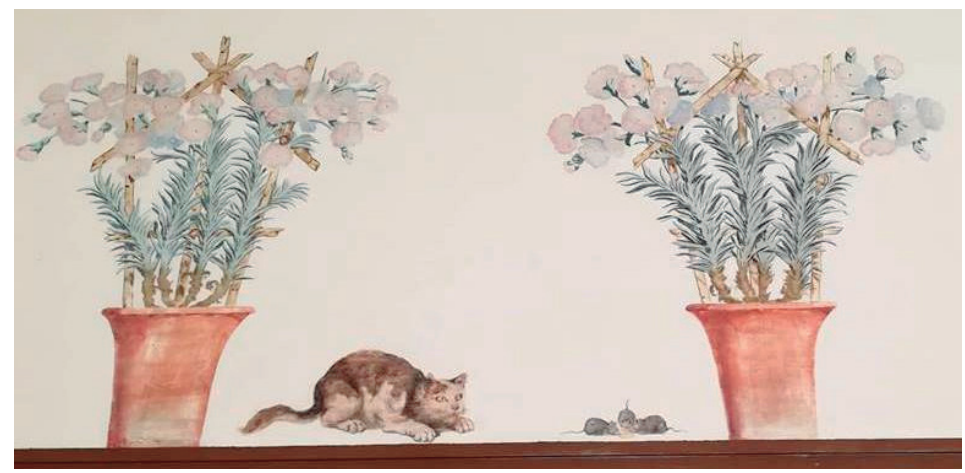

Imagem 6. Decoração de friso de sala de aula da Escola Primária de Alcântara, $1 .^{\circ}$ andar. $^{71}$

\footnotetext{
${ }^{69}$ Sjaak Braster, «Educational change and dutch classroom photographs».

${ }^{70}$ Ressalvo que irei recorrer a um conjunto de fotografias tiradas por mim, em maio de 2019, no âmbito de uma visita à Escola Primária de Alcântara. As Imagens 6 a 15 dizem respeito às diferentes salas de aula do edifício escolar. A minha análise terá, também, em conta a memória descritiva do projeto de decoração da Escola. A este respeito, consulte-se Raul Lino, «Decoração de Escolas Primárias».

${ }^{71}$ Foto do autor, maio de 2019.
} 


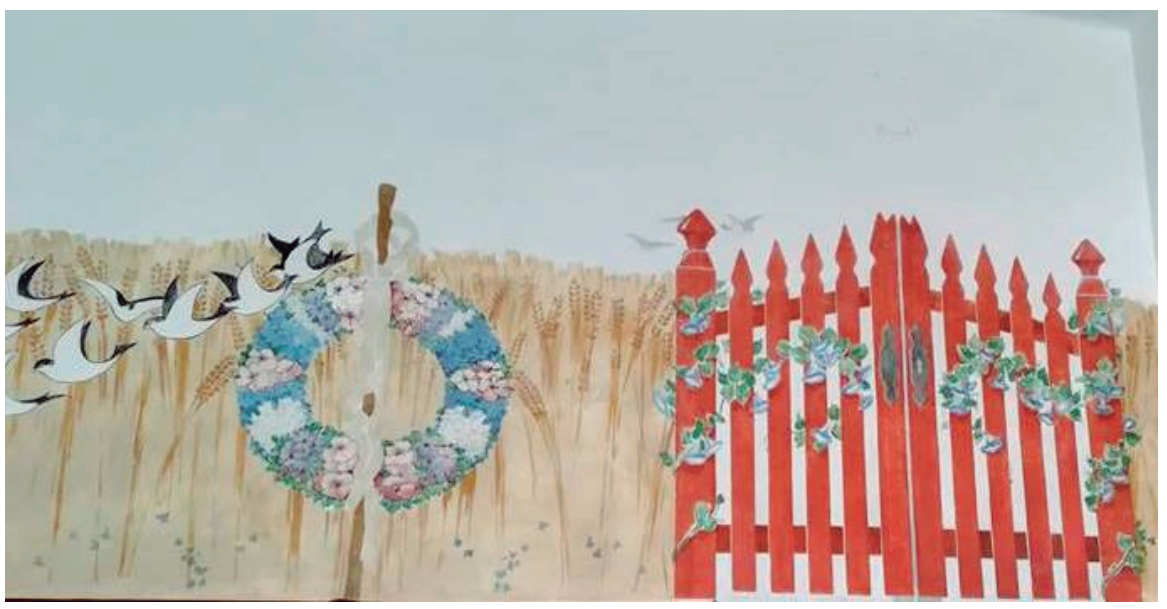

Imagem 7. Decoração de friso de sala de aula da Escola Primária de Alcântara, rés-do-chão. ${ }^{72}$

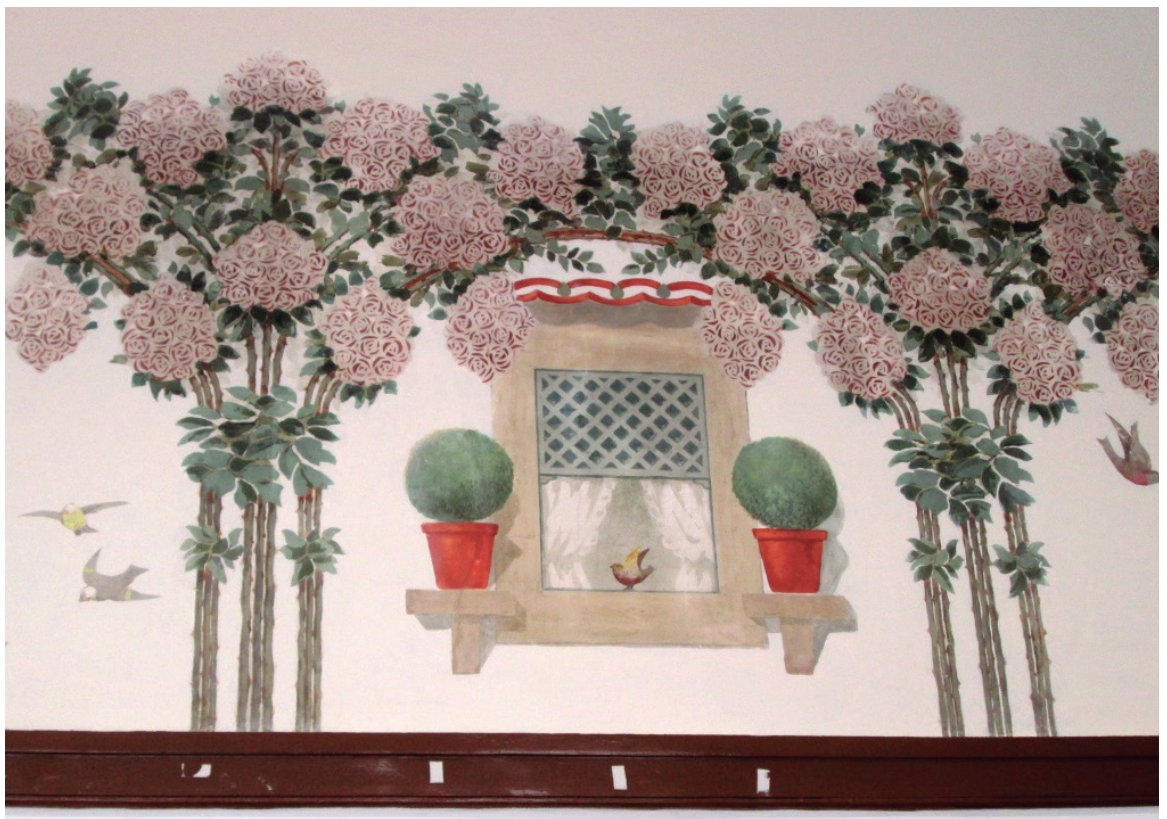

Imagem 8. Decoração de friso de sala de aula da Escola Primária de Alcântara, rés-do-chão. ${ }^{73}$

72 Foto do autor, maio de 2019.

73 Foto do autor, maio de 2019. 
Contrariamente, há duas salas de aula em que o elemento natural, por assim dizer, se afirma única e exclusivamente, a saber: no piso térreo, na sala em que estão representados coelhos; e, no piso superior, na sala em que figuram vários animais de capoeira.

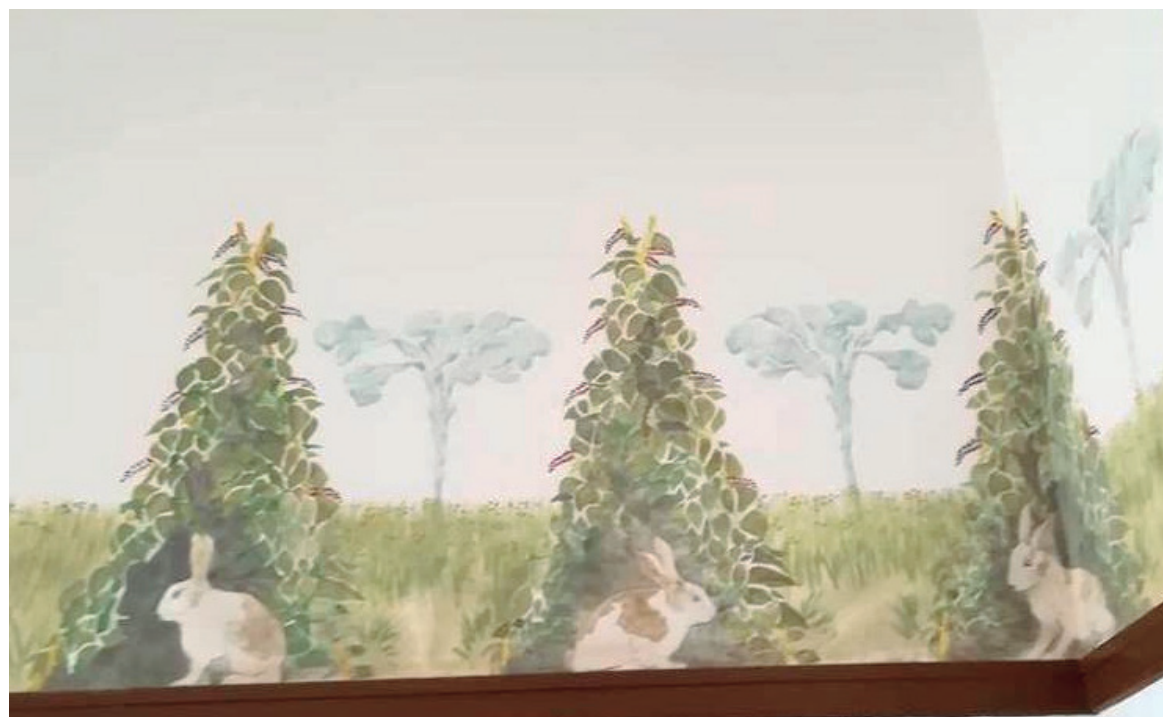

Imagem 9. Decoração de friso de sala de aula da Escola Primária de Alcântara, rés-do-chão. ${ }^{74}$

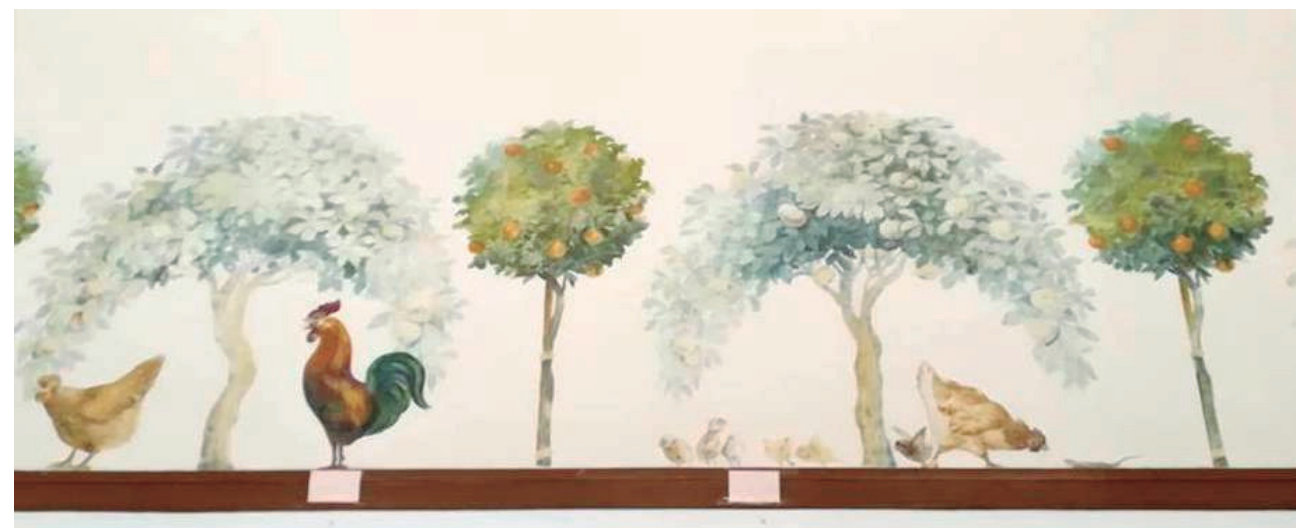

Imagem 10. Decoração de friso de sala de aula da Escola Primária de Alcântara, 1. ${ }^{\circ}$ andar. $^{75}$

\footnotetext{
${ }^{74}$ Foto do autor, maio de 2019.

75 Foto do autor, maio de 2019.
} 
Estamos, assim, perante um duplo registo (frequentemente, hibridizado): representação da Natureza (animais e plantas) e representação de ornamentação popular.

Por outro lado, afigura-se-me verosímil a ideia de que a decoração, entre outros motivos, pretendeu conferir identidade própria a cada uma das salas de aula. Defendo, aliás, como hipótese de trabalho, que Raul Lino seguiu uma das duas seguintes vias no esquema compositivo das pinturas dos frisos: i) ou definindo um tema genérico e repetindo várias vezes alguns elementos decorativos, criando, assim, unidade temática; ii) ou construindo a narrativa a partir de um elemento/ "personagem» central. Em relação à primeira situação, citem-se, a título de exemplo, as salas com representações de gatos, de guirlandas, de arcos florais e janelas, de aves de capoeira, de coelhos (ver Imagens 6 a 10) e, também, de limoeiros e sapos e de arranjos florais (ver Imagens 11 a 13); no segundo caso, refira-se a sala com a imagem de um cão (ver Imagem 14) e a sala com a imagem de uma cabra (ver Imagem 15), nas quais, na verdade, se destacam esses elementos/ «personagens» centrais.

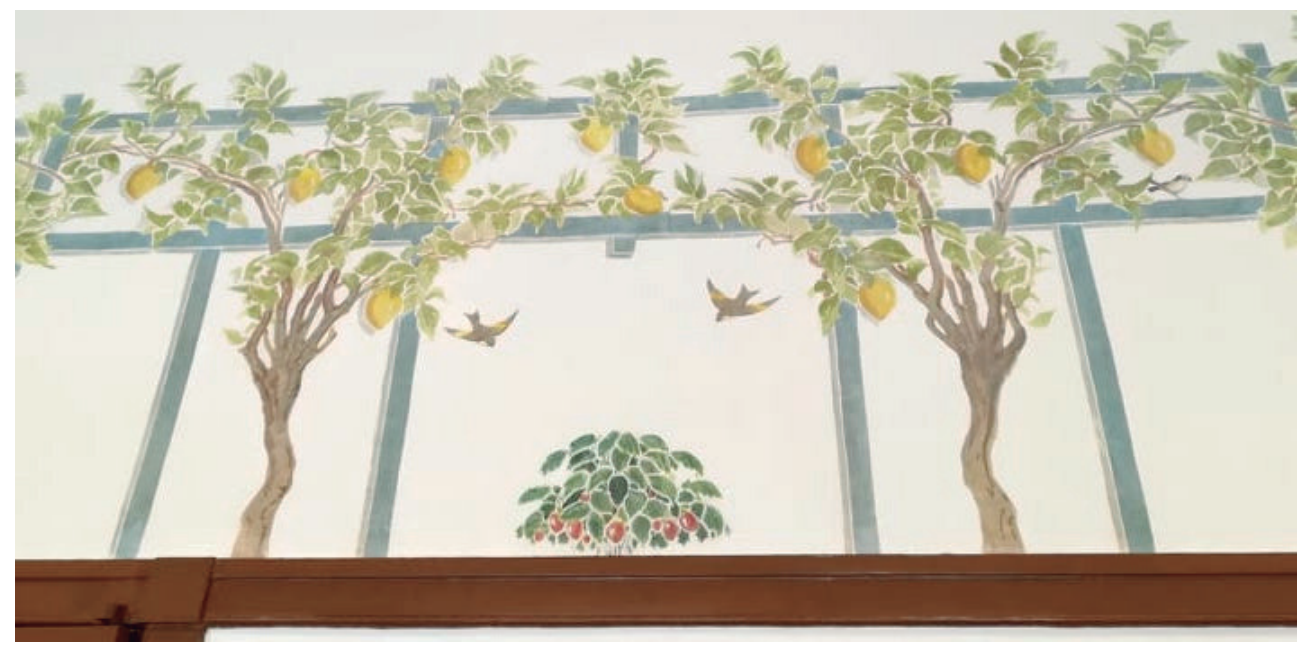

Imagem 11. Decoração de friso de sala de aula da Escola Primária de Alcântara, rés-do-chão. ${ }^{76}$

${ }^{76}$ Foto do autor, maio de 2019. 


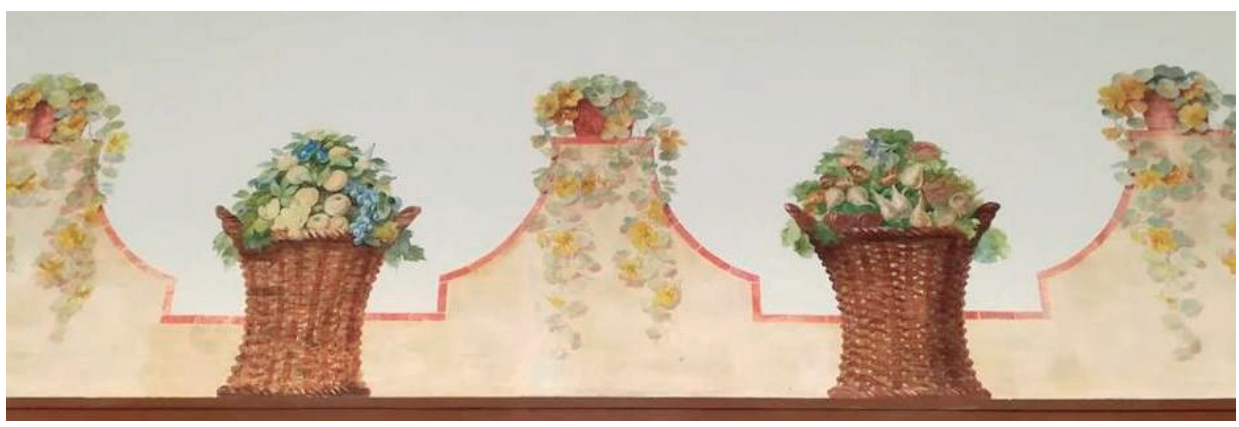

Imagem 12. Decoração de friso de sala de aula da Escola Primária de Alcântara, $1{ }^{\circ}$ andar. $^{77}$ Nota: Trata-se do único friso onde não são representados animais.

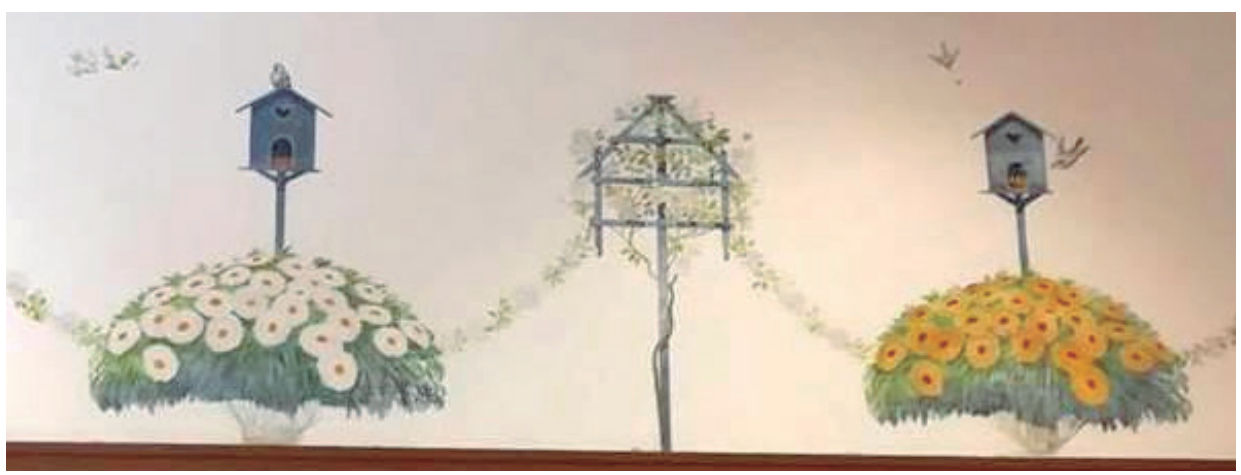

Imagem 13. Decoração de friso de sala de aula da Escola Primária de Alcântara, $1 .^{\circ}$ andar. ${ }^{78}$

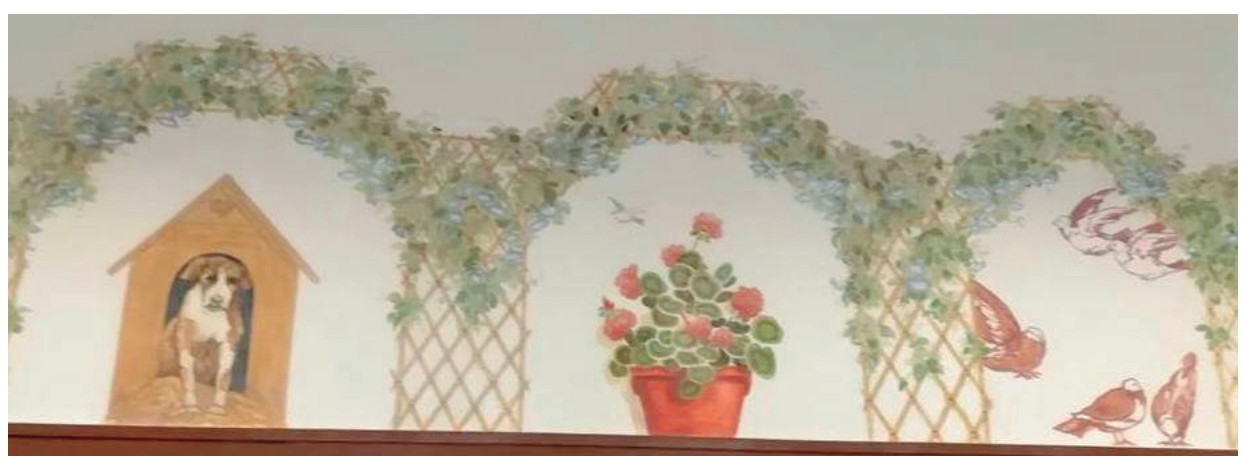

Imagem 14. Decoração de friso de sala de aula da Escola Primária de Alcântara, rés-do-chão. ${ }^{79}$

\footnotetext{
${ }^{77}$ Foto do autor, maio de 2019.

${ }_{78}$ Foto do autor, maio de 2019.

${ }^{79}$ Foto do autor, maio de 2019.
} 


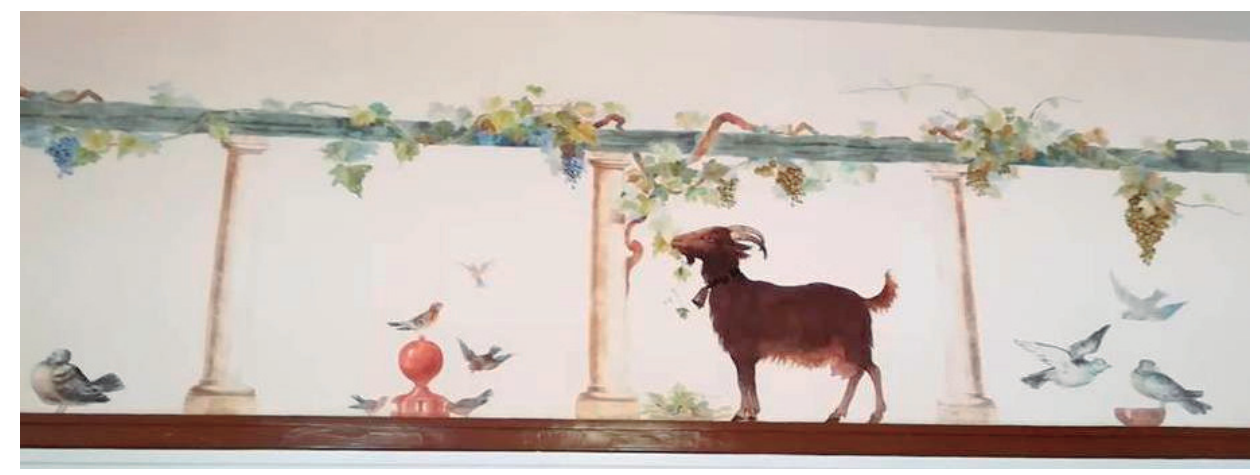

Imagem 15. Decoração de friso de sala de aula da Escola Primária de Alcântara, $1 .^{\circ}$ andar. ${ }^{80}$

No seu conjunto, as composições transmitem a ideia de harmonia e alegria: pássaros que bebem água de fontes, outros que se alimentam em pequenos comedouros, alguns que esvoaçam livremente, um gato que reage, como seria suposto, à presença de ratos, mas também a outros animais, um cão recolhido na casota, uma cabra que se alimenta tranquilamente..., representações enquadradas por elementos da Natureza e, em alguns casos, por ornamentações populares. A ideia comum à obra Animais nossos amigos - refletindo a experiência que Raul Lino teve enquanto coautor - é, no fundamental, a da valorização das qualidades (e idiossincrasias) de um certo número de animais. Em causa, a vontade de despertar nas crianças o carinho e o amor pelos animais. Para o arquiteto, na verdade, a imagem (e a narrativa que esta pode encerrar) desempenha um papel importante na formação de valores éticos de futuros cidadãos - cria, nomeadamente, condições para a memorização (através de processos visuais) de uma determinada mensagem. Aliás, a consciência de que a imagem tem um valor pedagógico (no melhor ou no pior sentido) é singularmente expressa por João de Barros. Na verdade, em novembro de 1911, tecendo rasgados elogios ao livro Animais nossos amigos, não deixa, ao mesmo tempo, de criticar a inclusão da figura do lobo - nas suas palavras, «esse terrível inimigo dos cordeiros, irmãos das criancinhas». ${ }^{81}$

\footnotetext{
${ }^{80}$ Foto do autor, maio de 2019.

${ }^{81}$ Citado em Cristina Nobre, Afonso Lopes Vieira: a reescrita de Portugal, 508. Desconheço se foi intencional, mas Raul Lino, no programa decorativo da Escola Primária de Alcântara, não incluiu animais e/ou elementos que, à partida, pudessem suscitar controvérsia.
} 
Uma última e breve nota, para afirmar que não são particularmente coincidentes os aspetos visuais e formais das ilustrações da obra Animais nossos amigos e a decoração dos frisos da Escola Primária de Alcântara. Ainda assim, é possível constatar que Raul Lino, em alguns casos, seguiu esquemas compositivos algo semelhantes. Veja-se, por exemplo, a similitude existente entre o modelo de colunas e o desenho da parreira representados na Imagem 15 e a composição que o arquiteto adotou na ilustração da última página do citado livro. Por outro lado, a decoração dos frisos aproxima-se das ilustrações de Animais nossos amigos, num duplo sentido: i) na afirmação de uma certa singeleza e candura (consentâneas com o desenvolvimento infantil); ii) no intento de definir composições que têm apenas os elementos/ personagens essenciais à narrativa - recorde-se que, para o arquiteto, a simplicidade devia imperar nas decorações escolares.

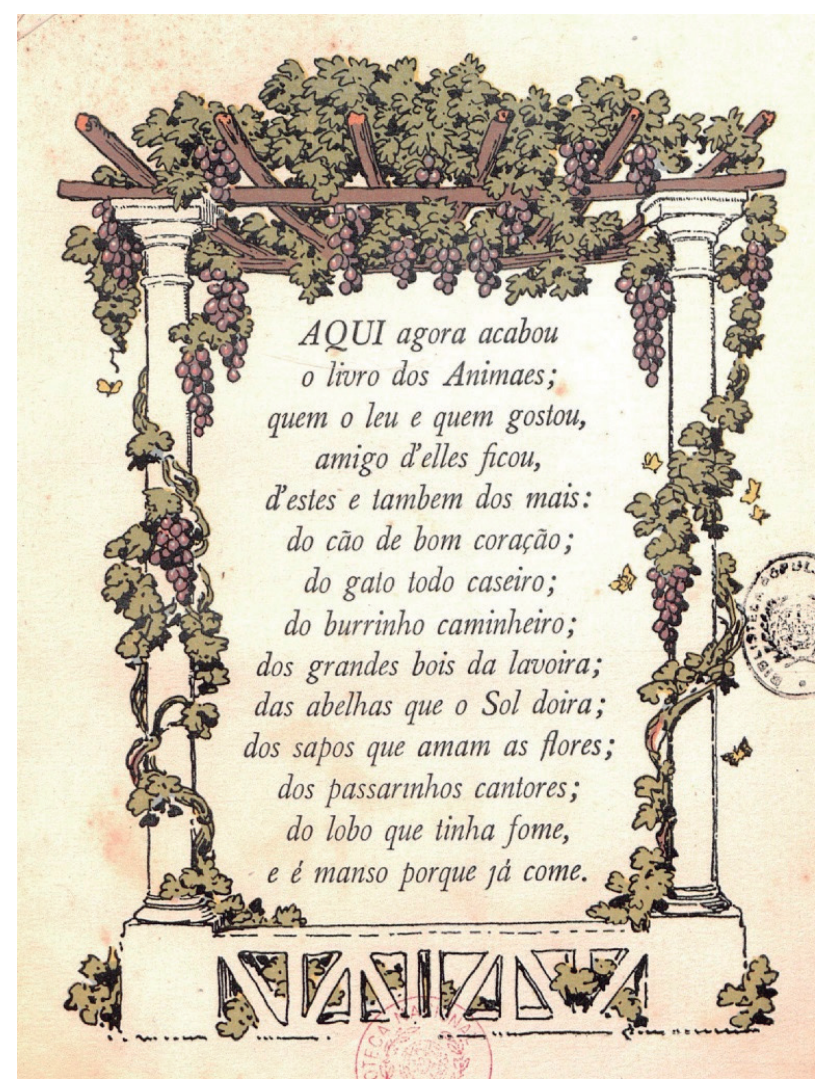

Imagem 16. Página final da obra Animais nossos amigos (1911); ilustração de Raul Lino. 


\section{CONSIDERAÇÕES FINAIS}

Raul Lino tinha um conceito muito preciso sobre o que deveria ser a educação estética da criança. Na verdade, em linha com referências internacionais, pugnará por uma escola mais atraente e pelo desejo de fazer a criança amar a Natureza e a arte. A importância que o ambiente visual tem para o arquiteto deve ser compreendida à luz da proposta de currículo defendida por Peter Cunningham, a qual inclui não só o conhecimento ensinado e aprendido em lições formais, mas também "values and attitudes conveyed in the ethos and environment of the school». ${ }^{82}$ Para Raul Lino, o que estava em agenda era promover a arte, de per si, como uma forma de inteligência e, ao mesmo tempo, favorecer o desenvolvimento pessoal da criança enquanto cidadão. É evidente, ainda, que o arquiteto integra o conhecimento da psicologia infantil para isso muito terá contribuído a interlocução privilegiada com personalidades como Afonso Lopes Vieira, João de Barros e João de Deus Ramos. A decoração da Escola Primária de Alcântara revela-nos, de facto, especial preocupação com o desenvolvimento da infância, designadamente, por ser sugestiva, apelativa e, assim, interpelar e despertar a curiosidade infantil. Recorde-se, apenas a título de exemplo, a representação no átrio da Escola de um grande papagaio de papel. Por outro lado, interessa sublinhar que a experiência desenvolvida pelo arquiteto na ilustração de livros, em particular, na obra Animais nossos amigos, influenciou a conceção da decoração da Escola Primária de Alcântara, especialmente pela ideia que comungou com Afonso Lopes Vieira e que acabou por recuperar; no essencial, a de um referente moral e ético expresso através da exaltação das qualidades e idiossincrasias dos animais e, também, do amor aos mesmos.

Outro tópico que importa destacar prende-se com a filiação do arquiteto no movimento Arts \& Crafts. Aquilo que procura fazer - à semelhança, aliás, do que se observa na Casa Vermelha, de William Morris - é reproduzir no interior do edifício escolar formas inspiradas na Natureza. Por outro lado, conforme constatámos, não faltam na Escola de Alcântara as estruturas de boas-vindas (lembre-se, uma vez mais, a

\footnotetext{
82 Peter Cunningham, «Art Between Architecture and Curriculum. Primary Education and Social Reconstruction in Post-War Britain», em The Decorated School. Essays on the Visual Culture of Schooling, eds. Catherine Burke, Jeremy Howard e Peter Cunningham (Londres: Black Dog Publishing, 2013), 46.
} 
representação de um enorme papagaio de papel no átrio de entrada), em linha com os fundamentos do citado movimento.

Considerando o programa decorativo dos frisos da Escola Primária de Alcântara, fica por perceber, à míngua de fontes (desconhece-se, por exemplo, de que forma foi pensada a distribuição das classes no interior do edifício escolar), se existe alguma lógica ou sequência entre salas e entre pisos.

\section{Nota sobre o autor}

Carlos Manique da Silva é Investigador da Unidade de Investigação e Desenvolvimento em Educação e Formação (Instituto de Educação, Universidade de Lisboa). Doutorado em Ciências da Educação (especialidade História da Educação), tem como áreas de interesse a circulação e difusão do conhecimento pedagógico, a escola graduada, o ensino mútuo e a arquitetura escolar. De entre as suas publicações, salientam-se: Escolas Belas ou Espaços Sãos? Uma Análise Histórica Sobre a Arquitetura Escolar Portuguesa (1860-1920), Lisboa, IIE, 2002; Publicações periódicas do Ministério da Educação. Repertório Analítico (1861-2009), Porto, Faculdade de Letras da Universidade do Porto, 2010. A Experiência das Juntas Escolares no Concelho de Mafra. Finais do Século XIX - I República, Porto, Faculdade de Letras da Universidade do Porto, 2018. Tem colaborado em vários projetos de investigação financiados pela Fundação para a Ciência e a Tecnologia (FCT), de que se destacam: Liceus de Portugal; Educação e Património Cultural: Escolas, Objetos e Práticas; Roteiros da Inovação Pedagógica: Escolas e Experiências de Referência em Portugal no Século XX; Memórias Resgatadas, Identidades (Re)construídas: Experiências de Escolarização, Património e Dinâmicas Educativas Locais. Foi professor visitante na Universidade Estadual de S. Paulo (Brasil).

\section{REFERÊNCIAS}

Barros, João. A República e a Escola. Lisboa: Aillaud, 1920.

Barros, João. «Edifícios escolares de Raul Lino». Atlântida 4 (1916): 331-336.

Barros, João. A Escola e o Futuro. Porto: Livraria Portuense de Lopes \& C. ${ }^{\text {a Su- }}$ cessor, 1908. 
Baudin, Henry. Les Constructions Scolaires en Suisse. Genève: Éditions d'Art \& d'Architecture, 1907.

Braster, Sjaak. «Educational change and dutch classroom photographs. A qualitative and quantitative analysis». Em The Black Box of Schooling. A Cultural History of the Classroom, editado por Sjaak Braster, Ian Grosvenor e María del Mar del Pozo Andrés, 21-37. Bruxelas: Peter Lang, 2011.

Buisson, Ferdinand. Nouveau dictionnaire de pédagogie et d'instruction primaire. Edition électronique, 2004 [1911].

Campagne, E. M. Diccionario Universal de Educação e Ensino Volume I. Porto: Livraria Internacional de Ernesto Chardron, 1886.

Chico, Pedro. Decoración Escolar. Madrid: Publicaciones de la Revista de Pedagogia, 3. ${ }^{\mathrm{a}}$ edição, 1933 [1. ${ }^{\mathrm{a}}$ edição de 1924].

Cunningham, Peter. «Art Between Architecture and Curriculum. Primary Education and Social Reconstruction in Post-War Britain». Em The Decorated School. Essays on the Visual Culture of Schooling, editado por Catherine Burke, Jeremy Howard e Peter Cunningham, 45-51. Londres: Black Dog Publishing, 2013.

Fernandes, José Manuel. «Olhando a obra de Raul Lino, a pensar em Frank Lloyd Wright: partindo do Arts \& Crafts, com a Natureza, o Orgânico e a Casa». Pós, 23, no 40 (2016): 168-189.

Figueira, Manuel Henrique. Um Roteiro da Educação Nova em Portugal. Lisboa: Livros Horizonte, 2004.

Grosvenor, Ian. "“To Act on the Minds of the Children”. Paintings into Schools and English Education». Em The Black Boss of Schooling. A Cultural History of the Classroom, editado por Sjaak Braster, Ian Grosvenor e María del Mar del Pozo Andrés, 39-56. Bruxelas: P.I.E. Peter Lang, 2011.

Lima, Adolfo. "Educação e ensino. Exposição de Arte na Escola». Germinal 5 (1916): 146-151.

Lino, Maria do Carmo Pimenta de Vasconcelos e Sousa. "As artes decorativas na obra de Raul Lino». Dissertação de mestrado, Lisboa, Universidade Lusíada, 1999.

Lino, Raul. «Raul Lino visto por ele próprio». Vida Mundial (Lisboa), no 1589, 21 de novembro de 1969.

Lino, Raul. «Decorações educativas e artísticas nas escolas primárias». Revista Municipal 67 (1955): 30-33.

Lino, Raul. «Decoração de Escolas Primárias. Memória Justificativa de uma Proposta para a Decoração da Escola de Alcântara». Boletim Oficial do Ministério de Instrução Pública 3 (1916): 191-194.

Lopes, Rui. «A moral, mural! As ideias nos mapas e quadros parietais». Dissertação de Doutoramento, Lisboa, Universidade de Lisboa, 2013.

Nobre, Cristina. Afonso Lopes Vieira: a reescrita de Portugal. Lisboa: Imprensa Nacional-Casa da Moeda, 2005. 
Nóvoa, António. Evidentemente. Histórias da Educação. Porto: Edições ASA, 2005.

Nóvoa, António (dir.). Dicionário de Educadores Portugueses. Porto: Edições ASA, 2003.

Oliveira, Carla Garrido de. "De “A Nossa Casa” a “Casas Portuguesas": Raul Lino entre livros, entre tempos, entre modos, entre modernos europeus». Em Celebrando a Nossa Casa (1918-2018) de Raul Lino. Antologia de Ensaios, coordenado por Paula André, 151-169. Lisboa: ISCTE.

Raul Lino: exposição retrospectiva da sua obra. Lisboa: Fundação Calouste Gulbenkian, 1970.

Renonciat, Annie. "The "Art at School” Movement in France. Goals, Ideas, Influence (1880-1939)». Em The Decorated School. Essays on the Visual Culture of Schooling, editado por Catherine Burke, Jeremy Howard e Peter Cunningham, 12-18. London: Black Dog Publishing, 2013.

Rhor, Sylvia. «Evolution of the Chicago Mural Movement. The Case of Lane Technical High School». Em The Decorated School. Essays on the Visual Culture of Schooling, editado por Catherine Burke, Jeremy Howard e Peter Cunningham, 19-27. London: Black Dog Publishing, 2013.

Rodrigues, Elsa. «Jardim-Escola João de Deus (Lisboa-Estrela)». Em Roteiros da Inovação Pedagógica. Escolas e experiências de referência em Portugal no século xx, coordenado por Joaquim Pintassilgo e Luís Alberto Marques Alves, 203-238. Lisboa: Instituto de Educação da Universidade de Lisboa, 2019.

Silva, Carlos Manique da. «Escolas, Higiene e Pedagogia: espaços desenhados para o ensino em Portugal (1860-1920)». Em Educação e património cultural: Escolas, objetos e práticas, coordenado por Maria João Mogarro, 93-117. Lisboa: Edições Colibri / Instituto de Educação, 2013a.

Silva, Carlos Manique da. «Raul Lino, protagonista de uma mudança na arquitetura escolar durante a I República Portuguesa». Educar em Revista 49 (2013b): 83-102.

Silva, Carlos Manique da. Escolas Belas ou Espaços Sãos? Uma análise histórica sobre a arquitetura escolar portuguesa (1860-1920). Lisboa: Instituto de Inovação Educacional, 2002.

Sluys, Alexis. "Importance de la culture esthétique dans l'éducation générale de l'enfant ». Em III Congrès International de l'Art Public, editado por Eugène Broerman, 1-41. Bruxelles : Imp. Schaumans, 1905.

Vieira, Afonso Lopes. "As nossas crianças». A Capital (Lisboa), 4 de fevereiro de 1912. 